\title{
Gathering the strands of thought
}

\author{
Trends in Cognitive Sciences \\ Editor Peter Collins \\ Elsevier. 12/yr. Europe $£ 475$, USA $\$ 775$ \\ (institutional); Europe $£ 85$, USA 1140 \\ (personal)
}

\section{Martha J. Farah}

The late twentieth century has seen a number of fundamental transformations in the study of the mind. For decades, ending in the 1960s, behaviourism dominated psychology. Its basic tenet was that observable entities such as stimulus and response were the only legitimate subject matter of a scientific psychology, and that the mental states intervening between stimulus and response were beyond the scope of objective inquiry.

This view was challenged by the advent of cognitive psychology, sometimes dated to the 1967 publication of a book by that name by Ulric Neisser. The explicit goal of cognitive psychology was to characterize, in objective, mechanistic terms, the mental machinery underlying such cognitive processes as perception, attention, learning, memory, language and problem-solving. A key idea in cognitive psychology was the 'computer analogy', according to which the mind is to the brain as the software is to the hardware of a computer. When viewed this way, mental states no longer seemed the airy fairy stuff of behaviourist critiques, but informationprocessing states of a physical mechanism, and hence well within the grasp of science.

Within ten years, the phrase 'cognitive science' had entered our vocabularies, and marked another important turn in the history of the field. Cognitive science is an interdisciplinary endeavour encompassing cognitive psychology, computer science, neuroscience and linguistics. The relevance of computer science and neuroscience is obvious for a field defined by its mind-brain/software-hardware analogy. Linguistics also became involved, partly because language is one of the more spectacular forms of cognitive ability possessed by humans, and partly because some believe that natural language is a representational system that shares properties with mental representation.

If ever a field needed a journal devoted to reviewing current trends, it would be a new interdisciplinary field like cognitive science. Only the youngest practitioners have had the benefit of formal training in more than one or two of its component disciplines, the rest of us having retooled as best we could midcareer. And whatever one's training, it would be difficult to keep entirely up to speed with all four strands of the subject. Trends in Cognitive Sciences is therefore most welcome.

Each issue features state-of-the-art reviews of a variety of areas in cognitive sci-

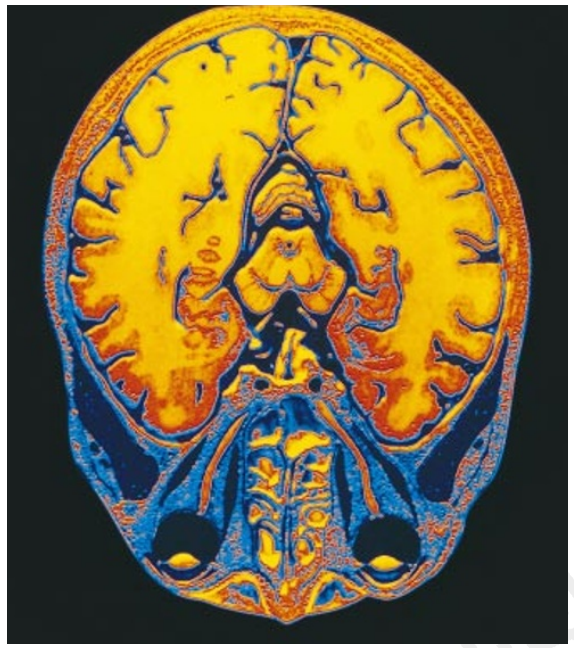

ence, mostly by well-known authorities. The editors have managed to enforce an accessible style of writing in most of the articles, and the overall look of the journal is attractive and fun. Indeed, whereas all of my other journals are shelved in my office at the university, my copies of Trends in Cognitive Sciences are piled on my bookcase at home. As solid as their scientific content is, they seem more like pleasure than business.

Martha J. Farah is in the Department of

Psychology, University of Pennsylvania,

Philadelphia, PA 19122, USA.

\section{Brains on call}

\section{Neuroscience-Net}

Editor John E. Johnson, Jr.

Scientific Design and Information. Online only, free.

http://www.neuroscience.com

\section{Todd C.Holmes}

Delightful as books and journals are, Internet-based publishing provides new capabilities for conveying scientific information, including rapid publication, search and link functions, running commentary on previously published articles, and vivid graphics. Theoretical scientists can set up web-based demos that allow interactive exploration by the reader, while scientists concerned with structure or dynamic processes can publish eye-catching movies. And for those of us who equate photocopying an article with reading it, web browsers offer the technological improvement of bookmarking.

Neuroscience-Net has made the brave step into electronic-only publishing with a journal for the neuroscience community. The journal subscription is free and is available to anyone with a computer and web access. It covers an admirably broad range of topics, divided by sections that include anatomy, pharmacology, molecular biology, physiology, psychiatry and psychology, and theoretical neuroscience.

Its editorial process is streamlined by FTP manuscript submission and e-mail peer review. Neuroscience-Net guarantees publication within two weeks of acceptance, a remarkable turnaround by any standard. A check of the date of acceptance on several articles confirms rapid publication. I found the associated graphics informative and clear, but the hardware and choice of web browser of individual readers will determine the final graphical quality. Unfortunately, Neuroscience-Net lacks linkage with other websites. Referenced papers are not linked to other journals, and other sections have unrealized potential for valuable links - the Materials and Methods articles, for example, could have links to reagent suppliers and instrument manufacturers (such links could provide potential revenue for an electronic journal as well). The articles are of high quality, but the most recently published at the time of writing was August 25, 1997.

Neuroscience-Net provides a forum for rapid publication of neuroscience articles, but it does not yet take full advantage of the capabilities of Internet-based publishing. This journal merits reading by neuroscientists of all stripes.

Todd C. Holmes is in the Department of Biology, New York University, New York, NY 10003, USA.

\section{Seen and heard}

\section{Child Psychology and Psychiatry Review}

Editors Linda Dowdney and Stephen Scott Cambridge University Press. 4/yr. USA \$112, elsewhere $£ 70$ (institutional); USA \$56,

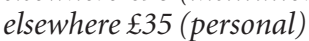

\section{Peter Bryant}

There are two different reasons why psychologists and psychiatrists are interested in children. One, an academic reason, is their interest in the origins of people's behaviour. We are bound to be in a better position to understand any aspect of behaviour if we know how it started, and most of people's behaviour (their solutions to intellectual problems, their prejudices, their moral principles) can be traced back to childhood. The second reason is a practical one. Many children need help from experienced clinicians, and they cannot afford to wait until the problems that afflict them - for example, autism, abuse, dyslexia and school phobia - have been thoroughly analysed and understood by psychologists and psychiatrists.

Of course, there is a certain tension 
between these two motivations, but on the whole it has been a creative tension. Academic psychologists have certainly benefited from the insights and experiences of people with clinical experience.

In this country, the enterprising and highly successful Journal of Child Psychology and Psychiatry has played an important part in making this contact between academic researchers and practitioners possible. For many years this journal has published scientific papers of a high standard, which usually interest people with clinical interests as well as academic readers.

Now the association that runs this journal has started a new enterprise: the Child Psychology and Psychiatry Review. Its purpose is to keep practitioners informed about the latest developments in research and in practice, and it sets out to do so in several ways. Each issue contains commissioned articles or sets of commissioned articles that provide up-to-date and highly readable reviews of a particular topic (for example, dyslexia, behavioural genetics). It also contains submitted articles and a journal monitor section with brief summaries of papers in other journals that are relevant to particular childhood problems, such as child abuse and educational difficulties. Most issues also have a section on legal matters. There is an occasional personal profile, each with an interview of a well-known child psychologist or psychiatrist. The new journal also contains a fairly lively correspondence section.

The articles are a mix of down-to-earth accounts of clinical practice and of up-to-date descriptions of theories on this or that aspect of childhood. They are all written clearly and with an attractive simplicity. The other sections of the journal are also interesting and informative, except for the personal profile section which has a parochial air and does not seem to me to add any stimulating new information. Apart from this, the editors of this new journal are providing busy practitioners with an entertaining but intellectually respectable account of current research. Peter Bryant is in the Department of Experimental Psychology, University of Oxford, South Parks Road, Oxford OX1 3UD, UK.

\section{The chaotic psyche}

\section{Nonlinear Dynamics, Psychology, and Life Sciences \\ Editor Stephen J. Guastello \\ Human Sciences Press. 4/yr. USA \$110, \\ elsewhere $\$ 130$ (institutional); USA \$35, elsewhere $\$ 41$ (personal)}

\section{H.Eugene Stanley}

The emerging field of nonlinear science has led to many advances and to many new journals - Fractals, Nonlinearity and Physica D to name just three. Recently, the concepts and methods of nonlinear science have also been finding interesting applications in the social sciences. Witness, for example, the popularity of applying methods of statistical physics to problems of economics and finance, an endeavour that has spawned many interesting ideas and topical conferences in Budapest, Palermo and Dublin under the rubric of 'econophysics'.

Other topics in the social sciences that appear to be amenable to the concepts and methods of statistical physics include problems associated with urban growth, where one quantitatively analyses the locations of homes, or foraging phenomena, where one asks for the most efficient strategy to find an object (food or lost car keys).

In all this work, there is no attempt to model the free will of the subject that determines the outcome, be they a Wall Street trader, a citizen building a home, or the foraging birds and bees. Presumably individuals do not exercise their free will, but learn efficient strategies and implement them.

In the fields of psychology and psychoanalysis it is hard to deny the role of free will, hence a journal devoted to the applications of concepts of nonlinear science to these disciplines would seem most interesting. The papers collected in the first issues span a range of problems of general interest in psychology, and bring to bear on them concepts such as catastrophe theory and fractal theory. Out of these marriages arise children with unfamiliar names such as 'collective intelligence' and 'stochastic determinism' (an oxymoron at first sight).

Will this moderately priced journal fulfil the need for a genuinely interdisciplinary journal on nonlinear science applied to the social sciences? It seems doubtful. The editorial board contains no physical scientists or practitioners of statistical mechanics, the discipline most active in nonlinear science. Further, there is a strong emphasis on psychology rather than on a wider range of social sciences. Moreover, if the initial issues are any guide, there is a tendency in many of the papers to simply 'talk' rather than report new experiments, simulations or scientific

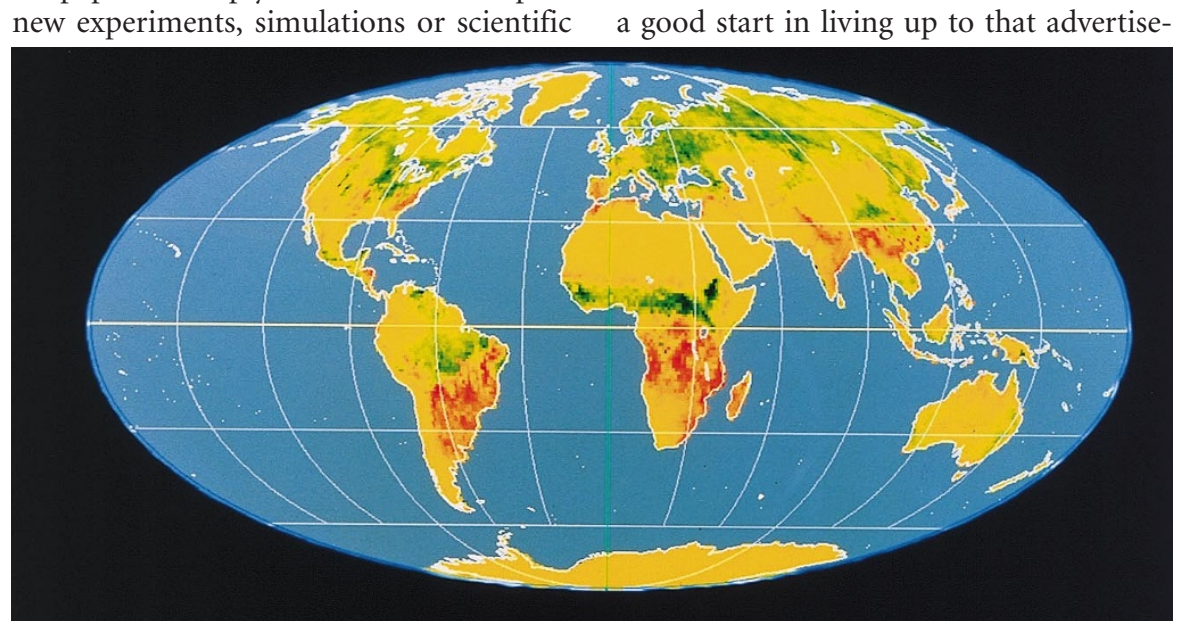

The fixing of $\mathrm{CO}_{2}$ (green) and its release through plant decomposition (red) in a typical June. models. There are even a few misunderstandings of some of the principles of nonlinear science.

These limitations might be overcome, and the journal fulfil its potential, if it were to broaden its horizons and undertake rigorous refereeing procedures.

H. E. Stanley is at the Center for Polymer Science, Boston University, 147 Bay State Road, Boston, MA 02215, USA.

\section{No waste of trees}

\section{Boreal Environmental Research}

Editors-in-chief Hannu Lehtonen and

Sylvain Joffre

Finnish Zoological and Botanical Publishing Board. 4/yr. FM500, \$100 (institutional);

FM200, $\$ 40$ (personal)

\section{David W.Schindler}

No single ecological type, or 'biome', covers more first-world countries than the Boreal, with forests that extend over most northerly latitudes of Eurasia and North America, including Scandinavia, the former Soviet Union, Canada, and the northern USA. For the past 30 years, residents and environmental organizations of these countries have expressed their displeasure at the rapid exploitation of tropical forests, not noticing that boreal ecosystems under their very noses were quietly being sacked at an equally astounding rate. The boreal zone also contains more than 90 per cent of the world's lakes. Its vast wetlands are pivotal ecosystems in greenhouse gas balances.

In the past, research on boreal lands and waters has been diffused through a number of more general ecological publications, making it difficult to find. A journal that advertises itself as devoted to boreal science in the broadest sense, emphasizing holistic approaches to boreal problems by experimental, monitoring, theoretical and modelling approaches, is therefore long overdue.

Volumes one and two of Boreal Environmental Research, from 1996 and 1997, make a good start in living up to that advertise-

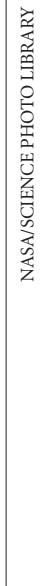

